\title{
Jornalismo e literatura: hibridismos culturais no comentário
}

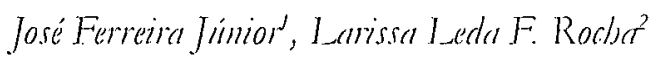

\begin{abstract}
Resumo: O jornalismo contemporâneo, especificamente o opinativo, apresenta-se hoje como um lugar privilegiado para o empréstimo, trocas e doaçies entre a litcratura e o jornalismo. A narrativa hibrida, que rem dai, propõe que se tire os trajes formais do jormalismo opinativo editorialista ou mesmo das matérias diarias, para vestir a informação de modo mais informal, trazendo pessoalidade e sensibilidade. Trata-se de uma hibridização de frontciras. Discutindo ainda a questão em torno do real no jornalismo e novos formatos de produção textual, este trabalho tra\% como objeto de análise o género do comentátio, exemplificado na obra do jormalista josias de Soura e a fase concreta do pocta Haroldo de Campos.
\end{abstract}

Palavras-chaves: hibridismo; jornalismo; literatura; mignação conceitual

Abstract: The modern journalism, specifically the opinion one, it should today as in a special position in lending, exchanging and donating to literature and journalism. The mixtured description comes from the intention of taking off the formal environment from editting opinion journalism or eren from the daily news, to take on the information in an informal way bringing personality and sensitively. It is about a boundary mixture. Discussing the point about what is real in journalism and new text productions styles, this work brings a study about comment analysed in Josias de Souza production and at concrete phase of the poet Haroldo de Campos.

Keywords: mixture; journalism; litcrature; conceptual migration

1 Professer da Unicersidade Federal do Maranhas li mestre e doutor em Comu-

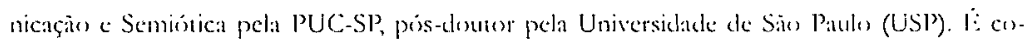

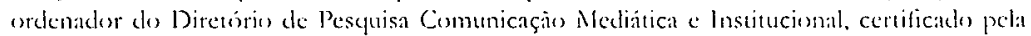
Universidade Federal do Mamano e pelo CNPy Autor dos lives "Arenal da palara" "Capas de jomal", além de artigos publicados em periodicos e cm anivis diversos congressos.

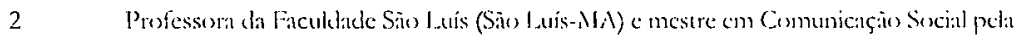

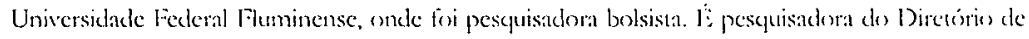

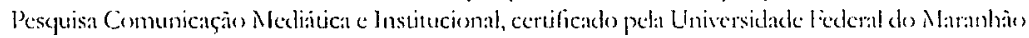
e polo CNly. Possui artiges publicados em anas de congressos come lneereom a SBPyer. 
Ainda que jornalistas, escritores e teóricos se queixem - e critiquem - um certo afastamento entre literatura e jornalismo, tal ação não parece nem corresponder ao que é possível de ser observado no discurso jornalístico e em suas narrativas de hoje, nem ao que parece ser um caminho desejável diante de uma mídia que ao distribuir a informação já o faz a um público que precisa de algo a mais do que o lead.

As críticas e juras de afastamento ${ }^{3}$, se dão seja pela denúncia do empobrecimento dos textos jornalísticos, ausência de leitores para um material mais sofisticado ou a ausência de espaço no jornalismo dado à literatura em sua forma direta. Ora, sempre será possível encontrar pensadores dedicados a pontuar as divergências e as separações entre literatura e jornalismo e, de modo algum, ousamos afirmar que elas não existam - a exatidão do jornalismo, por exemplo, afastase da narrativa literária, bem como sua dependência excessiva a um certo mito de narrar a realidade. No entanto, há um coro expressivo de pensadores que se debruçam sobre a questão que a pensa de modo inversamente proporcional e é com eles que nos filiamos.

Sim, o texto jornalístico pode usar elementos próprios da literatura para dar àquele discurso uma nova plástica, nova roupagem e, se nos permitem a metáfora, despir a informação do terno e gravata enrijecido, formal do jornalismo editorial e das matérias jornalísticas diárias e vesti-la com roupas de banho, trazendo informalidade, pessoalidade e sensibilidade, tão próprias a formatos como o comentário e a crônica. Não se trata apenas de usar elementos próprios da literatura, mas de permitir uma hibridização de fronteiras, uma mestiçagem que plasma novas negociações de sentido e oferece ao leitor algo além de um texto marcado pelo rigor do mito da verdade e que o respeita em sua capacidade receptiva e intelectual.

Mesmo as experiências mais extremas de narrações híbridas como o New Journalism ${ }^{4}$ - o jornalismo literário norte-americano, cujo manifesto mais contundente do gênero foi escrito por Tom Wolfe no ano de 1973, tendo o movimento se mostrado a partir de 1960 com nomes como Truman Capote - onde se faz um relato mesma língua. In: CASTRO, G., GALENO, A. Jornalismo e literatura: a sedução da palavra. São Paulo: Escrituras, 2002.

4 Sobre o assunto, ver: RESENDE, F. Texituaçōes ficção e fato no novo jornalismo de tom wolfe. São Paulo: Annablume; Fapesp, 2002. Ou ainda ver: PENA, F. Jornalismo literário. São Paulo: Contexto, 2006. 
jornalístico marcado pela presença mais de verossimilhança do que de realidade, ou ainda o Realismo Fantástico - movimento literário latino-americano de autores como Gabriel Garcia Márquez c Mário Vargas Lhosa que mistura narrativas fantásticas a elementos reais - é preciso admitir que a vida vivida, a vida real, é a inspiraçào para relatos jornalísticos, literários ou híbridos. Como nos lembra Ventura (2001, p. 41-42), 'Dizia-se: o jornalista trabalha com a realidade, sua matéria-prima é o real, concreto e verdadeiro. Já a literatura usa como material a ficção. Era um esquema, e funcionava. Hoje as coisas estão mais complicadas'. E completa mais adiante 'ao embaralhar tudo isso, enriqueceram os dois conceitos: (...) Literatura e (...) Jornalismo'.

O conceito de real é profundamente pantanoso, bem como as possibilidades do jornalismo de narrá-lo ou mesmo de representá-lo. O discurso jornalístico, é coerente afirmar, por mais que tenha vocação para narrar um real está, permanentemente, recheado de contornos ficcionais. $\mathrm{E}$ isso é explicado por vários aspectos, dos quais citaremos apenas alguns. Sem precisar entrar em polemicas filosóficas, é possivel afirmar que a realidade carrega em si a idéia de mudança permanente, logo o princípio de sua própria contradiçào, desencadeando um processo de transformação constante. 'A linguagem, ao tentar representar o real, funciona como mediadora da relaçào dialética entre sujeito e mundo real em contínua mudança' (SATO, 2002, p. 30). O real e sua verdade, buscados obsessivamente pelo jornalismo - ao menos como mito - são inalcançáveis. Montase por tramas e recortes, escolhas e conexões, por ocultar e mostrar. Silva (2002, p. 49) nos diz que o jornalismo precisa falar do que é verdadeiro, com verossimilhança, mas lembra quépor trás do texto, escrito, há outro texto, inscrito. Por trás do tema, descrito, existem outros assuntos, transcritos. Só é verossimil aquilo que, ao expressarse, inclui alguma falsidade, uma deformaçào (de forma ação)'.

Apagar as marcas do sujeito, como faz o jornalismo ao narrar sempre na terceira pessoa garantindo a impessoalidade do discurso, produz uma fala esvaziada, que oculta o processo social de criaçào da notícia e cria um efeito de objetividade, uma ilusão de autonomia. Efeito falso, este. O relato jornalístico é ficcional ao, por exemplo, causar a impressão de que o evento está acontecendo no momento da leitura, valorizando-se o instante - o que é potencializado sobremaneira em tempos de jornalismo on-line marcados pela ausência de deadline e novas configurações espaço-temporais. É também ficcional 
ao ocultar os esquemas para captação de notícias, o que inclui o uso das fontes que podem constituir posições estereotipadas - e em geral, o fazem. A consulta às fontes, a ação, frequentemente, não aparece, ou seja, mostra-se 'apenas a linguagem, como esforço, como redundância. A notícia, como procedimento teórico, levou a tipificações que redundaram em editorias que direcionam o público ao colocar um fato neste ou naquele rótulo' (SATO, 2002, p. 32). Dito de outra maneira: as formas de ver do jornalista constroem uma realidade, esta passada como verdade ao público. Estes profissionais trabalham com o acontecido presente em um passado imediato, mas o que contam não é a realidade, mas sua representação e ela vem carregada fortemente pela subjetividade de quem vê. Ora, o ser humano não expõe, puramente, as coisas. $O$ jornalismo não é um espelho, o discurso jornalístico não é o real.

O jornalismo está sempre em um presente, narrando o que é passado, porém um passado muito próximo, atual. Faz uma reconstrução desse passado, mas sem jamais conseguir recuperar o real em sua totalidade. Enquanto a literatura pode transfigurar a pessoa real em personagem fictícia, utilizando-se do real possível, o jornalismo busca o real/verdade para compor a narrativa, mas enfrenta a influência de conhecimentos anteriores, de conceitos pré-concebidos, de histórias de vida, de experiências que antecederam o fato. (...) A verossimilhança pode ocupar o lugar da verdade como matéria-prima do texto jornalístico' (VICCHIATTI, 2005, p. 92).

Como nos diz Silva (2002, p. 116) ao falar sobre coberturas jornalísticas de guerra, 'a ficção quando bem manejada oferece uma saudável irresponsabilidade'. Segundo o autor, ao não alertar para as pessoas - as fontes - com as quais conversa que é um jornalista, a face mais verdadeira da guerra - da notícia - pode oferecer-se a ele, já que 'a ficção é a história clandestina das sociedades, as versões desautorizadas, livres de qualquer censura ou fronteiras'. No que concorda Menezes (2002, p. 166): 'acho que, muitas vezes, a percepção da presença de jornalistas em determinados locais pode mudar os rumos de determinada história'. O curioso é que o autor não está referindo-se à presença do jornalista como um catalizador para o aparecimento da verdade, mas justamente ao seu ocultamento, sua reconfiguração, sua ficcionalização. 
Não é objetivo deste trabalho focar suas atençòes nos complexos conceitos de realidade, ficção, verossimilhança e veracidade, apesar de compreendermos a importancia dos mesmos para a discussão. Querenos mais nos preocupar em indicar o hibridismo narrativo entre literatura e jornalismo e, para isso, usar como objeto de análise parte da obra do jornalista Josias de Souza, do portal UOL e do jornal Folha de S. Paulo 5 .

As certezas que nos orientavam há pouco tempo atrás, identificando de un lado o discurso do real - fornecido pelo jornalismo - e de outro, oposto, o discurso do ficcional - responsabilidade da literatura - nos abandonaram. Em seu lugar surgem questões que apontam para uma outra proposta narrativa, um jornalismo permeado pela literatura, que se mistura com ela e mantém um relacionamento marcado por doações e empréstimos de um a outro. Pena (2006, p. 13) nos aponta logo de saída a complexidade instaurada na questào e a amplitude da procura por um conceito de jornalismo literário:

Significa potencializar os recursos do fornalismo, ultrapassar os limites dos acontccimcntos cotidianos, proporcionar visóes amplas da realidade, exerecr plenamente a cidadania, romper as correntes burocráticas do lead, cvitar os definidores primários c, principalmente, garantir perenidade e profundidade aos relates. No dia seguinte, o texto deve servir para algro mais (it) que simplesmente cmbrulhar peixe na feira.

É ainda Pena (2006) que nos atenta para as várias conceituações e classificações que jornalismo literário pode ter, variando conforme o autor, ou grupos de autores, que se cledica a pensar a questão. Inicialmente, o jornalismo literário pode ser relacionado a determinado momento histórico onde escritores assumiam, nos jornais, funçócs de cronistas, autores de folhetins, editores, o que remonta ao sécu10) XIX. Pode ser entendido como criticas ou resenhas feitas sobre obras literárias publicadas nos jornais. Pode ser ainda o New Journalism, já citado neste trabalho, ou ainda textos que incluem biograblicado o liven "A histinia real", do 1994, cm parceria com Gilletto Dimenstein. $A$ obra revela os bastidenes da primedra cleç̧âo de Fernando Hentique Cardoso a Presidencia da Republicá. Ea anda ganhador do Premio lesso de fornalismo de $2001 \mathrm{com}$ a sírie de reportagens batizada de "Os papéis secretos do exćrcito", publicada ma Follo de S. laulu. 
fias, romances-reportagens e ficção jornalística. O autor debruça-se para trabalhar cada uma das classificações, a nós interessa mais neste momento pensar no jornalismo opinativo e, mais especificamente, no comentário como palco privilegiado onde acontecem as apropriações, empréstimos e doações que podem ser feitas do jornalismo à literatura e vice-versa.

Sim, literatura e.jornalismo são territórios diferentes, não são a mesma coisa. Mas o que os separa é, por vezes, mais frágil do que o que os une. Apropriações e entrelaçamentos mostram-se a todo instante e nem precisamos sair dos jornais diários para ver isto. Exercícios jornalísticos como a crônica e o comentário, por exemplo, tem a ousadia de nos apresentar, quase cotidianamente que é possível usar os pontos de intersecção entre ambos para a construção de uma narrativa híbrida, até porque, é menos inibidor à informação mostrar-se mais leve, menos enrijecida e pouco audaciosa em qualquer forma de experimentação quando se apresenta como jornalismo opinativo.

Vicchiatti (2005) nos diz que o jornalismo, pode ao mesmo tempo ser fiel aos fatos e avançar no uso de elementos da literatura, o que não faz com que os textos percam características próprias da narrativa jornalística. Tirar o paletó do jornalismo editorial, da matéria jornalística diária - massacrada, podemos dizer, pelo lead - e vestir a narrativa com roupa de banho, permite que regras básicas e conceituais sejam respeitadas, e ainda sejam somadas certa dose de qualidade e vida aos trabalhos. Os textos tornam-se mais humanos.

O que ocorre na construção dessa narrativa híbrida é a busca da arquitetura textual complexa da literatura para retratar a informação factual caracteristica do jornalismo. O uso de elementos da literatura não implica a alteração das características intrínsecas ao texto jornalístico. (VICCHIATTI, 2005, p. 87).

São em exercícios jornalísticos como a crônica e o comentário que podemos ver com mais facilidade o encontro dos gêneros. Naturalmente, o jornalismo opinativo dá-se melhor nesse encontro, pois não é tão massacrado pelos rigores técnicos do jornalismo, pelas exigências da produção de um discurso colado ao real. A ótica e a ética do jornalismo opinativo são outras, mais livres, mais libertárias, deixando claro que não estamos aqui falando de um jornalismo opi- 
nativo editorialista, este também sufocado pelos rigores das técnicas jornalísticas e comprometimentos editoriais do veículo. Busca-se em comentários e crônicas não o narrar urgente dos fatos - apesar de ser a atualidade também uma de suas características - senào mais um determinado tipo de olhar, uma certa forma de interpretaçào, o desvelar de certas tramas que envolvem os acontecimentos. O modo como comentários e crônicas, por exemplo, apropriam-se do mundo real, suas interaçōes com ele e a forma como o expõe aos leitores fazem toda a diferença.

Focaremos nossa atenção, a partir daqui, mais no comentário, estilo exercido pelo jornalista Josias de Souza, cujos textos são objeto de nossa análise. Marques de Melo (2003) nos aponta nào apenas características inerentes ao jornalista que opta pelo comentário, mas as próprias caracteristicas do tipo textual. O comentarista é o juiz da coisa pública. Opina sem impor. Opina sem paixão. Conduz sem se alinhar' (MELO, 2003, p. 11.3). Funciona como un líder de opiniào, com farta bagagem cultural, logo capaz de emitir opiniōes e valores a respeito de acontecimentos que são do conhecimento de todos, é um observador privilegiado, e um observador que procura manter certo distanciamento das ocorrèncias.

O foco orientador não é a postura do veículo, a opiniào expressada não é editorialista. Há uma tônica de independência en relação à linha editorial. O cidadão comum o busca justamente por esta sua característica. A capacidade de ler o cenário contemporáneo, apresentando uma possibilidade de compreensão e valoração, oferecendo um modo coerente para comportar-se diante dos fatos, ć profundamente sedutor para o público que procura formas de interpretaçào dos fatos que se desenvolvem no espaço público.

O comentário trata do acontecimento recente, real. Nem sempre apresenta uma opinião explícita, mostrando-se também pelo raciocínio apresentado, pelos caminhos da argumentaçào. $\mathrm{O}$ comentarista precisa ser alguém muito bem formado, já que deve julgar os acontecimentos velozmente e prever algumas de suas conseqüências. 'O ofício do comentarista é justamente estabelecer o nexo que liga os fatos. E estes só adquirem sentido no tempo' (NELO, 2003, p. 115). Ver além da primeira aparência é o maior desafio do comentário, o que exige do jornalista sintonizaçào constante com suas fontes. $\mathrm{E}$, apesar de exigir especialização - nào há comentaristas de assuntos gerais - o comentário, raras vezes, apresenta-se de modo conclusivo. 
Mais livre que o editorial, o comentário, de acordo com Melo (2003), estrutura-se em duas partes. Inicialmente é feita uma síntese do fato e a enunciação de seu significado e posteriormente é apresentada a argumentação que sugere seu julgamento. E este fato, sob o qual se debruça, não precisa, necessariamente, ser o mais importante da pauta do jornal, fatos de menor abrangência podem merecer ser foco de um comentário. Sendo uma narrativa do cotidiano, o comentário possui suas especificidades, como manter uma conexão muito próxima com a atualidade, 'sendo produzido em cima dos fatos que estão ocorrendo. Vem junto com a própria notícia. Por isso, é difícil de ser realizado, exigindo muita argúcia no sentido de evitar prognósticos não confirmáveis' (MELO, 2003, p. 115).

O comentário só consegue fluir, pois, em um ambiente de liberdade de expressão. Eis, então, que tenha sido um gênero sufocado até à morte durante os anos de ditadura militar no Brasil. Não apenas a censura era responsável por tal efeito, mas também o fechamento das fontes de informação. Com a abertura política, o comentário volta a ser praticado no jornalismo, com força. Por suas características e liberdade quanto à linha editorial dos veículos, o comentário mostra-se como um lugar privilegiado para pensarmos em um texto que, ainda obedecendo às regras jornalísticas, ousa ir além e hibridizar-se com a literatura, promovendo um balé equilibrado entre um e outro onde as experimentações são bem-vindas.

Morin (1995) e (2000) nos fala sobre um migrar de conceitos, de uma complementaridade entre uma coisa e outra que empresta complexidade à sociedade, de um certo relacionamento, contexto de informações. O conhecimento organiza a informação em um contexto e confronta as idéias em um conjunto.

O conhecimento só é conhecimento enquanto organização, relacionado com as informações e inserido no contexto delas. (...) Os conhecimentos fragmentados só servem para usos técnicos. Não conseguem conjugar-se para alimentar um pensamento capaz de considerar a situação humana no âmago da vida (MORIN, 2000, p. 16-17).

Já os conceitos, afirma, viajam e é este movimento que os mantém vivos. É justamente o seu movimento, sua movimentação 
- clandestina ou não - que dá oxigenenio às disciplinas, que dá vicha, evitando um congestionamento da ciência. É a troca, esse ir e vir, esse contaminar-se no processo, mas deixar de si, que mantém viro. Fis, também o que a literatura e o jornalismo tèm a ganhar quando permitem viagens de conceitos, estruturas e técnicas: vida!

() alvorecer desse paradigma nos leva a lugares de observação nos quais o cxame do comentátio - pensade, estruturido e escrito à mancira da presia concreta, no caso de Josias de Souza - precisa, necessariamente, estar situado em ambiente interdisciplinar, porque a Jeitura e a análise de tal peça sào um exercício para o qual o ollhar critice tem de estar amalgamado com a Teoria literária, o Design Gráfico e a Estética Informacional, da quial sĩo expocentes Max Bense (1975) e Nbraham Noles (1987).

Sem se furtar ao compromisso com a análise, Josias de Sourá estrutura o comentário em uma tessitura na qual brotam arquiteturas risuais cuja função é dilatar os efeitos que a leitura prodù, conticlos no plano semântico. Ou seja: a análise do cenário presente e as "apostas" para o futuro são feitas, nesses momentes, com recursos literários, alterando a rotina e sinalizando para as nosas formas de organizar o textos verbal-escrito.

O jornalista já rem há tempos exercitandos essas pecjuenals ousatdias formais. Há exemplos de tal prática no comentário que jesias de Souza assinava na página 2 , no primeiro caderno, da liollha de $S$. Paule, hábito que manteve no blogs (portão UOL), sendo ainda mais frecuüente.

F́ acentuadamente emblemático o comentário, postades $\mathrm{cm}$ 1" de jancires de 2006, cujo tema era "um balanço" do ano anterior, caractcrizado pele denúncia de pagamento sistemático, em dinheirs vive, a parlamentares aliados ao governo federal - o fanoso escindalo do mensalào. O texto se assemetha a um poema de Haroldo de Campo, Galáxias, cuja cadeia de significantes, aliado a sonoridade tra\% consigo a icéia de contintum, ràão pela qual cabe a analogia como mattéria de reflexão acercal do avizinhamento entre jornalisno e literatural no plano da tessirura construtiva.

Vejaumos o inicis des poema da fase concretista de f laresde de Campos:

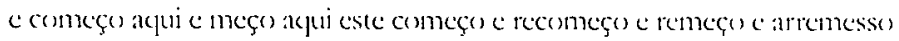
e aquit ne meço yuandos se vive sob a espécie da viagemo que importa 
não é a viagem mas o começo da por isso meço por isso começo escrever mil páginas escrever milumapáginas para acabar com a escritura para começar com a escritura para acabarcomeçar com a escritura por isso recomeço por isso arremeço por isso teço escrever sobre escrever é o futuro do escrever sobrescrevo sobrescravo $\mathrm{em}$ milumanoites milumapáginas ou uma página em uma noite que é o mesmo noites e páginas mesmam ensimesmam onde o fim é o começo

Todo esforço é concentrado na sonoridade, na espacialidade, sem negligenciar o aspecto da movimentação de arranjos verbais, configurando-se tudo naquilo que o próprio Haroldo de Campos intitulava de poema verbivocovisual.

Observemos o texto opinativo de Josias de Souza:

\section{5, um ano do "C"...}

\section{No Planalto}

Canalocracia. Casa Civil conspurcada. Comissário chefiando camarilha. Cruza de convento com cabaré. Conjunção carnal. Cônjuges convenientes. Concubinato caro. Coligação comprada. Corrupção centuplicada. Chaga. Câncer. Cancro. Camorra. Coletas. Contascorrentes. Cofres cercados. Caixa caudalo $\$$ o.

Companheirada com comichão. Contra-revolução do contracheque. Camundongos na colméia. Casta de carrapatos. Canaã corporativa. Colosso. Cada centímetro coletivizado. Cosmopolitismo caipira. Conforto. Colchas de cetim. Chambre. Caviar. Champanhe. Churrascadas. Conhaque. Charutos cubanos. Catarse.

Congresso carcomido. Comprometimento. Contramão. Contravenção. Cooptação. Clientela congênita. Coleira. Cabresto. Continuidade. Corpo a corpo. Conluios à contraluz. Conchavos condenáveis. Costuras de convés. Cambalachos chulos. Convicções corcundas. Cueca carregada. Careca comprometido. Cachês cabeludos. Cheques compensados. Consórcio comissionado. Controle.

Confiança contrariada. Corifeu conta. Canta coro consistente. Cartada cabal. Conspiração de cocheira. Castidade comprometida. Correria. Curto circuito. Confusão. Controvérsia. Cochichos. Confidências. Coações. Cizânia. Conflito. Colisão. Cisma. Choque. Camorra conflagrada. Constrangimento. Citados, coadjuvantes confessam. Cobaias. 
Contrição cênica Comandante cegor? Cilada de camandas? Cascata. Comédia. Cinismo. Cabotinismo. Cambalacho. Coreogratia caricat ta. Conversa cerebrina. Conho crispado. Cara de cedro. Conhece as cercanias, daro. Condescendencia consciente. Calos consentick Contemplação cinica. Contemporização canhestrat. Cumplicilade. Cadi os conspiradores?

Clamor contra a cambada. Cólera camburão, cadcla, calabouço, cassete, carnificina Cenáro corrosios. Consumiçias. Comjuntura comgestionada. Chicanas. Camaradagens. Camullagens. Comalidaçoes. Cafajestadas. Cachorradas. Cacarejos. Cassaçoes adentes Corretios capengas. Caçoada conhecida. Circo contumar.

Camnal 2006. Costume cronoligico. Consagraçio. Corommento. Cliches. Cordoes. Coreograbas. Confetes Colombinas. Caboclas. Cerveja Cachaça Concordia.. Camaradagem comtagiante Contentamento coletiso. Consciencias caladas.

Convulsân contida Conformismo. Candide\% Continuidade Codadania congelada. Crise caduca, comalescente (eticismo. (unzas. (alvirio. 2005 do "C"... Cheiros a carniça. Chegan!

Há, sem dúvida, convergências no aspecto formal, ressialtando-se, obviamente, os objetires distintos na instancia da produção de sentidos. Trata-se da marerialização da proposta moriniana da migração conceitual, atitude com a yual a ciencia de oxigenat conceituação unirersalista cuja credencial está, justamente, na inceireza e na consciência na construção analógica. () pressuposter alicerçader não estaria longe dacuilo enunciado pelo poeta Antonio Machade, citado por Morin (1987): 'Caminante no hay' camino, se hace camino no) caminhar'.

() texto de Josias de Souza esquiva-se do lugar-comum, temtação da qual não escapam os comentaristas em datas como al passagrem de ano. É ó tempo das retrospectivas, no calendario jornalistice, cuja "gramática" sofre ligeitas mudanças de veiculo para veiculo de comunicação, conservando-se a forma croneskigica ce a apelo a remas rotinciros: celebridades, catástrofes, festas, cte.

Se nos postarmos, de outro modo, diante dos mosimentos literários, reremes cnunciados com riés polítice, com entase na formulaçào implicita. A construção textual, cm bases inowadorits, foi uma 
constante das chamadas vanguardas, sobretudo ao longo do século $\mathrm{XX}$, cuja expressão variou conforme o projeto poético, as injunções políticas, o nivel de experimentação socialmente aceita.

É importante não perder de vista que, nesse caso, não há hegemonia de centros econômicos que, quase sempre, ditam também o repertório cultural. Para Amalio Pinheiro, experimentações como as do poeta chileno Vicente Huidobro adiantaram-se a outras, mais intensamente divulgados, como as de Apollinaire. Pinheiro vê, na obra de Huidobro, os elementos para uma idéia de vanguarda diferente daquela habitualmente apresentada.

É importante que se note o fato de que o poeta chileno, ao invés de remeter a modernidade, pelo processo de similaridade regressiva, ao encantamento mecânico e futurofascistóide de si mesma (feito de acréscimos temáticos), repensa-a em termos de arranjos de seus materiais, da conexão entre seus códigos. (PINHEIRO, 1990, p. 64).

Se não hierarquização por parte dos centros hegemônicos, no plano da literatura, tampouco se pode afirmar que haja, na esfera do jornalismo, posturas submissas, pelo menos no âmbito da forma, aos núcleos de poder político e econômico. Um exemplo significativo é a programação visual de alguns jornais brasileiros que, aqui e acolá, destacam-se no plano internacional, ganhando prêmios e consolidando estilos.

Todo esse aspecto colateral está, explicitamente, manifesto nos comentários de Josias de Souza, cujo diálogo se mostra à medida que nos faz relembrar de manifestações poéticas da canção popular de movimentos como o tropicalismo, já sobejamente estudado na interface com a poesia concreta.

O texto sobre o aniversário de 48 anos de Brasília, postado em 21 de abril de 2008, não é apenas emblemático. É um texto síntese da proposta verbal colocada ao longo dos anos pelo jornalista. A analogia, desta feita, é com a letra da canção de Gilberto Gil, Batmakumba.

Vejamos, primeiro, a letra de Gil e, na seqüência, o comentário de Josias de Souza. 


\section{Bamakumba}

Batrokumbayeyê batmakumback

Batmakumbaycyĉ́ batmakumbac

Batmakumbayêyê batmakumla

Batmakumbayêêe batmakum

Barmakumbaycyê batman

Batmakumbayêyê bat

Batmakumbayéy ba

Batmakumbayêy'

Batmakumbaye

Batmakumba

Batmakum

Batman

Bat:

Ba

Bat

Barman

Batmakum

Batmakumba

Batmakumbayé

Batmakumbayềè

Batmakumbayèyè ba

Batmakumbayéyé bat

Batmakumbayêyè batman

Batmakumbayêyê batmakum

Batmakumbayêyê batmakumban

Bamakumbayèề batmakumbacba 
Brasília faz 48 anos e ingressa na 'Idade Média' JK

Pó

Céu

Ermo

Sonho

Cerrado

Aivoroço

Niemeyer

Dá, não dá

Lúcio Costa

Modernidade

Mexe, remexe

Risca e rabisca

Ah! Plano Piloto

Ou vai ou racha!

Lobbies, trejeitos

Jeitinhos, arranjos

'Quanto levo nisso?'

Inicio do novo Brasil

O público privatizado

Desbravamento moral

Canteiro de obras: lama

Máquinas e tratores: lama

Movimentos pesados: lama

Uma cleptocracia emergente

País de inocentes e cúmplices

De repente, o cerrado vira mar

Mar de gente; humilde e ingente

Gente pungente; daqui, dali, d'acolá

Cimento, tijolo, ferro, aço e vidro

Suor, lágrima, 'concreto amado'

Grita, sussurra, bate e levanta

Horizonte largo, tempo curto

Correria, pressão, algaravia

Avenidas, prédios, euforia

Monumentos curvilíneos

Teatro, eixos, Catedral

Supremo e Congresso

O Palácio do Planalto

Praça dos 'poderes'

Lá se vão 48 anos

A cidade é duas

$\Lambda$ modernidade

A Idade Média

Absenteísmo

Clientelismo

Espertezas

Culpados?

Ora, nós!

$O$ voto

Vesgo

Torto

Cego

Oco

Dá

Dó 
Há similitude, mais do que há comunhaios integral, aloraçando (1 pressuposto verbivocorisual, alinhavado por Harolde de Campos e liberto dos grrilhoses da integridade da palar ra que sufoca a sonoridade (no caso de letra de Gilberto (iil) e da hipotaxe imperiosa, longe da qual, par muitos, não haveria produçio jornalística, sobretude cm gèneros opinatisos - haja vista o circunspecto editorial.

Uma assertiva final nãe pexieria deixar de ratificar a caráter interdisciplinar, a mobiliclade conceitual e a intermitente perspecriva sistêmica. () 'caminante' que procura scu 'camino' as andar, do poema de Antonio Nachado, é nosso farol. Conseyüentemente, segruindo as pegadas de Edgar Morin (1987, p. 25), an se reportat :1 Nietssche, o métode pode vir no fim. 


\section{Referências}

AZEREDO, J. C. Letras e comunicafão: uma parceria no ensino de língua portuguesa. Petrópolis: Vozes, 2001.

BENSE, Max. Pequena estética. São Paulo: Perspectiva, 1975.

CAMPOS, Haroldo. Metalinguagem \& outras metas. 4. ed. São Paulo: Perspectiva, 1992.

CASTRO, G., GALENO, A. Jornalismo e literatura: a sedução da palavra. São Paulo: Escrituras, 2002.

MELO, J. M. Jornalismo opinativo: gêneros opinativos no jornalismo brasileiro. 3.ed. rev. amp. Campos do Jordão: Mantiqueira, 2003.

MENEZES, R. Relações entre a crônica, o romance e o jornalismo. In: CASTRO, G., GALENO, A. Jornalismo e literatura: a sedução da palavra. São Paulo: Escrituras, 2002.

MOLES, Abraham. O cartaz: 2. ed. São Paulo: Perspectiva, 1987.

MORIN, E. O método I. Lisboa: Europa-América, 1987. tuto Piaget, 1995. Introdução ao pensamento complexo. 2.ed. Lisboa: InstiA cabefa bem feita: repensar a forma, reformar o pensamento. Rio de Janeiro: Bertrand, 2000.

PENA, F. Jornalismo literário. São Paulo: Contexto, 2006.

PINHEIRO, Amalio. Huidobro: visualidade e mobilidade. Face. São Paulo, 1990, v. 3, n. 1, p. 61-72, janeiro/julho.

SATO, N. Jornalismo, literatura e representação. In: CASTRO, G., SILVA, J. M. O que escrever quer calar? Literatura e jornalismo. In: CASTRO, G., GALENO, A. Jornalismo e literatura: a sedução da palavra. São Paulo: Escrituras, 2002.

VENTURA, Z. Jornalismo e literatura: alianças e diálogos. In: CASTRO, G., GALENO, A. Jornalismo e literatura: a sedução da palavra. São Paulo: Escrituras, 2002.

VICCHIATTI, C. A. Jornalismo: comunicação, literatura e compromisso social. São Paulo: Paulus, 2005. 